http://dx.doi.org/10.32929/2446-8355.2020v29n1p106-117

\title{
CARACTERÍSTICAS BROMATOLÓGICAS E PRODUTIVIDADE DO CAPIM TIFTON 85 SUBMETIDO A FONTES DE ADUBOS NITROGENADOS
}

\author{
Karen Andreon Viçosi ${ }^{1 *}$, Nathan Bernardo de Amorim² ${ }^{2}$, Maria Alice da Silva Brito ${ }^{3}$, Adilson \\ Pelá ${ }^{4}$

\footnotetext{
${ }^{1}$ Mestre em Produção Vegetal pela Universidade Estadual de Goiás, Campus Ipameri-GO. *E-mail do autor correspondente:karen_vicosi@ hotmail.com.

${ }^{2}$ Engenheiro Agrônomo pela Universidade Estadual de Goiás, Campus Ipameri-GO.

${ }^{3}$ Discente de Engenheira Florestal da pela Universidade Estadual de Goiás, Campus Ipameri-GO.

${ }^{4}$ Professor Doutor da Universidade Estadual de Goiás, Campus Ipameri-GO.
}

Recebido: 27/08/2019; Aceito: 20/03/2020

RESUMO: A adubação nitrogenada é fundamental para a manutenção de alta produtividade e qualidade das pastagens para a alimentação animal. Entretanto, diante das diversas fontes nitrogenadas disponíveis, é essencial saber a qual fonte o Tifton 85 é mais responsivo. Desse modo, o trabalho tem como objetivo avaliar a resposta do capim Tifton 85 submetido a fontes de adubos nitrogenados. O experimento foi conduzido em um delineamento inteiramente casualizado, com seis adubos nitrogenados e três cortes (6x3), com quatro repetições. Os adubos nitrogenados foram: testemunha; ureia, ureia Nitro Gold; ureia Policote; sulfato de amônio e cama de frango. Foram realizados três cortes, realizados a cada 30 dias, sendo que em cada corte foi realizada da poda do capim a $10 \mathrm{~cm}$ e recolhimento da matéria verde para análise a avaliação da altura, número de perfilhos, massa seca, relação folha/colmo e massa seca por perfilho, produtividade e teor de proteína bruta. A maior produtividade do Tifton 85 foi com sulfato de amônio no primeiro corte, com aumento de $270 \%$. A relação folha colmo aumenta em função corte, enquanto a massa seca por perfilho diminui. Em relação ao teor de proteína bruta, a adubação nitrogenada promove aumento de proteína nas folhas, com aumento de até $164 \%$. A adubação nitrogenada proporciona melhoria das características produtivas e bromatológicas com destaque para o sulfato de amônio. A produtividade do capim Tifton 85 decresce em função do número de cortes, enquanto ocorre um aumento da relação folha/colmo, o que indica a necessidade do parcelamento da adubação nitrogenada.

Palavras-chave: Cynodon. Capim-bermuda. Pastagem. Proteína bruta. Nitrogênio.

\section{BROMATOLOGICAL CHARACTERISTICS AND PRODUCTIVITY OF TIFTON 85 GRASS SUBMITTED TO SOURCES OF NITROGEN FERTILIZERS}

\begin{abstract}
Nitrogen fertilization is fundamental for maintaining high productivity and quality of pasture for animal feed. However, given the various nitrogen sources available, it is essential to know which source Tifton 85 is most responsive to. Thus, the objective of this work is to evaluate the response of Tifton 85 grass submitted to different sources of nitrogen fertilizers. The experiment was conducted in a completely randomized design with six nitrogen fertilizers and three cuts $(6 \times 3)$, with four replications. The nitrogen fertilizers were:
\end{abstract}


control; urea, Nitro Gold urea; urea Polyote; ammonium sulfate and chicken litter. Three cuts were made every 30 days, and in each cut was performed pruning the grass at $10 \mathrm{~cm}$ and collecting green matter for analysis the evaluation of height, number of tillers, dry mass, leaf / stem ratio and mass. tiller dry matter, yield and crude protein content. The highest productivity of Tifton 85 was with ammonium sulfate in the first cut, with $270 \%$ increase. The stem leaf ratio increases as a function of cut, while the dry mass per tiller decreases. Regarding the crude protein content, nitrogen fertilization promotes increased protein in the leaves, with an increase of up to $164 \%$. Nitrogen fertilization provides improvement of productive and bromatological characteristics with emphasis on ammonium sulfate. The yield of Tifton 85 grass decreases as a function of the number of cuts, while there is an increase of the leaf / stem ratio, which indicates the need for nitrogen fertilization.

Key words: Cynodon Bermuda grass. Pasture. Crude protein. Nitrogen.

\section{INTRODUÇÃO}

O capim tifton 85 é um híbrido do gênero Cynodon, proveniente da África do Sul, oriundo de cruzamentos intra e interespecíficos, e tem como características um porte mais elevado, colmos compridos, folhas mais extensas e de coloração verde escuro, grandes rizomas e estolões de rápida expansão (BURTON et al., 1993). Pode ser utilizado tanto na bovinocultura de corte de leite, quanto na criação de ovinos.

O nitrogênio é o principal nutriente para a manutenção da produtividade das pastagens, além de maximizar o rendimento da matéria seca de gramíneas forrageiras, devido ao fato de ser constituinte das proteínas (DUPAS et al., 2016; GALINDO et al., 2018a), essencial para o crescimento vegetal e para a alimentação animal. Como a maioria das pastagens no Brasil recebe pouca ou nenhuma adubação, as estratégias que promovem a utilização do $\mathrm{N}$ em forragens podem ter impactos positivos significativos na produtividade das pastagens, na sustentabilidade agropecuária e redução dos impactos ambientais, reduzindo a degradação das pastagens, especialmente se o fertilizante for aplicado de maneira correta (TAFFAREL et al., 2016; BORGES et al., 2017).

Dentre os fertilizantes nitrogenados mais utilizados na agricultura, o sulfato de amônio, a ureia e o nitrato de amônio, a ureia é a fonte mais empregado no Brasil e no mundo, correspondendo a cerca de $60 \%$ dos fertilizantes comercializados, por apresentar maior concentração de $\mathrm{N}(46 \% \mathrm{~N})$ e menor custo por unidade de nutriente (BERNARDES et al., 2015; CHAGAS et al., 2017). Entretanto, a indústria tem buscado alternativas tecnológicas para reduzir as percas por volatilização ureia no solo, como adubos revestidos com polímeros, que se enquadram no grupo dos fertilizantes de liberação lenta, e o uso de adubos encapsulados ou recobertos (fertilizantes solúveis revestidos).

Desse modo, o uso da adubação nitrogenada em pastagens é uma opção para intensificar os sistemas de produção animal, aumentando a produtividade e com consequência elevando a taxa de lotação animal (TIECHER et al., 2016). Diante disto, o trabalho tem como objetivo avaliar a resposta do capim Tifton 85 submetido a fontes de adubos nitrogenados. 


\section{MATERIAL E MÉTODOS}

O experimento foi desenvolvido em casa de vegetação da Universidade Estadual de

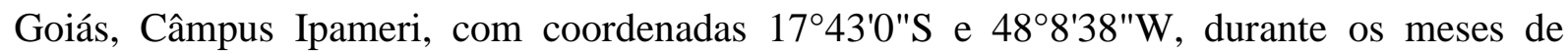
setembro de 2017 a fevereiro de 2018. A unidade experimental foi constituída de vaso padrozinados com nove quilos de solo cada, a 5,57\% de umidade. Os resultados obtidos na análise de solo foram: $\mathrm{pH}\left(\mathrm{CaCl}_{2}\right)$ 5,1; P (Mehlich) $1,2 \mathrm{mg} \mathrm{dm}^{-3}$; M.O 9,0g dm${ }^{-3} ; \mathrm{K} \mathrm{17,0} \mathrm{mg}$ $\mathrm{dm}^{-3}$; Ca 0,8 $\mathrm{cmolc} \mathrm{dm}^{-3} ; \mathrm{Mg} \mathrm{0,3} \mathrm{cmolc} \mathrm{dm}^{-3} ; \mathrm{H}+\mathrm{Al} \mathrm{2,2} \mathrm{cmolc} \mathrm{dm}^{-3}$; B 0,19 mg dm${ }^{-3}$; Cu 1,9

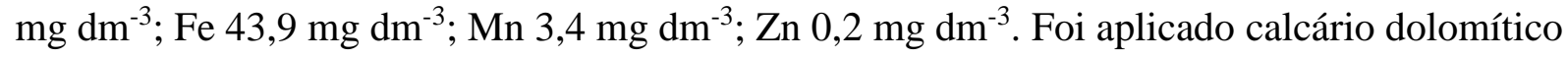
visando elevar a saturação por bases para $60 \%, 30$ dias antes da semeadura.

O plantio do capim Tifton 85 foi realizado através do transplantio de uma muda com três nós sadios por vaso. Dez dias depois, foi realizado adubação na forma de solução nutritiva, aplicando-se $50 \mathrm{~mL}$ por vaso da solução composta de $200 \mathrm{mg} \mathrm{dm}^{3} \mathrm{de}_{2} \mathrm{O}$, na

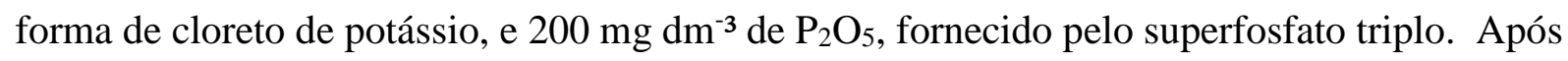
o pegamento e crescimento das mudas, 60 dias após o plantio, foi realizado a poda do capim a $20 \mathrm{~cm}$ para promover homogeneidade das unidades experimentais, juntamente com a aplicação dos tratamentos, constituídos de diferentes fontes adubos nitrogenados, aplicados na dose de $200 \mathrm{mg} \mathrm{dm}^{-3}$ de N.

O experimento foi conduzido na forma de fatorial em um delineamento inteiramente casualizado, com seis adubos nitrogenados e três cortes $(6 \mathrm{x} 3)$, com quatro repetições. Os adubos nitrogenados foram: testemunha (sem adubação nitrogenada); ureia (46\% de N), ureia Nitro Gold (37\% de N e $16 \%$ de S); ureia Policote (43\% de N), sulfato de amônio (20\% de N e $22 \%$ de $\mathrm{S})$ e cama de frango $(2 \%$ de $\mathrm{N})$. Foram realizados 3 cortes, realizados a cada 30 dias.

Em cada corte foi realizada a avaliação da altura e número de perfilhos, além da poda do capim a $10 \mathrm{~cm}$ e recolhimento da matéria verde para análise. A mensuração da altura foi realizada através de regra milimetrada, sendo que o critério para medição da altura das plantas correspondeu à distância do nível do solo até o horizonte superior das folhas no dossel, enquanto que o número de perfilhos foi obtivo através de contagem manual. Em seguida, foi realizada a separação manual das folhas e do colmo da matéria verde para obtenção da matéria fresca, seca, produtividade estimada e análise de nitrogênio.

A massa seca do colmo e massa seca foliar foi obtida após armazenamento do material em sacos de papel para secagem em estufa de circulação forçada de ar, em temperatura de $60^{\circ} \mathrm{C}$ por $72 \mathrm{~h}$ para a obtenção da matéria seca, com posterior pesagem em balança de precisão. A massa seca total foi obtida através da soma da massa seca do colmo e das folhas. A razão da massa folha/colmo foi obtida pela simples divisão da massa seca foliar pela massa seca do colmo. Através dos dados obtidos, foi estimado a produtividade da cultura $\left(\mathrm{kg} \mathrm{ha}^{-1}\right)$.

Todas as variáveis foram submetidas à análise de variância a 5\% de probabilidade e, quando constatadas diferenças significativas, foram submetidas ao teste de média Scott-Knott com auxílio do programa R (TEAM, 2013). 


\section{RESULTADOS E DISCUSSÃO}

$\mathrm{O}$ uso de diferentes adubos nitrogenados influenciou na altura do capim Tifton 85 somente no $2^{\circ}$ corte (Figura $1 \mathrm{~A}$ ), com destaque para a testemunha sem adubação nitrogenada e cama de frango que obtiveram maiores valores.
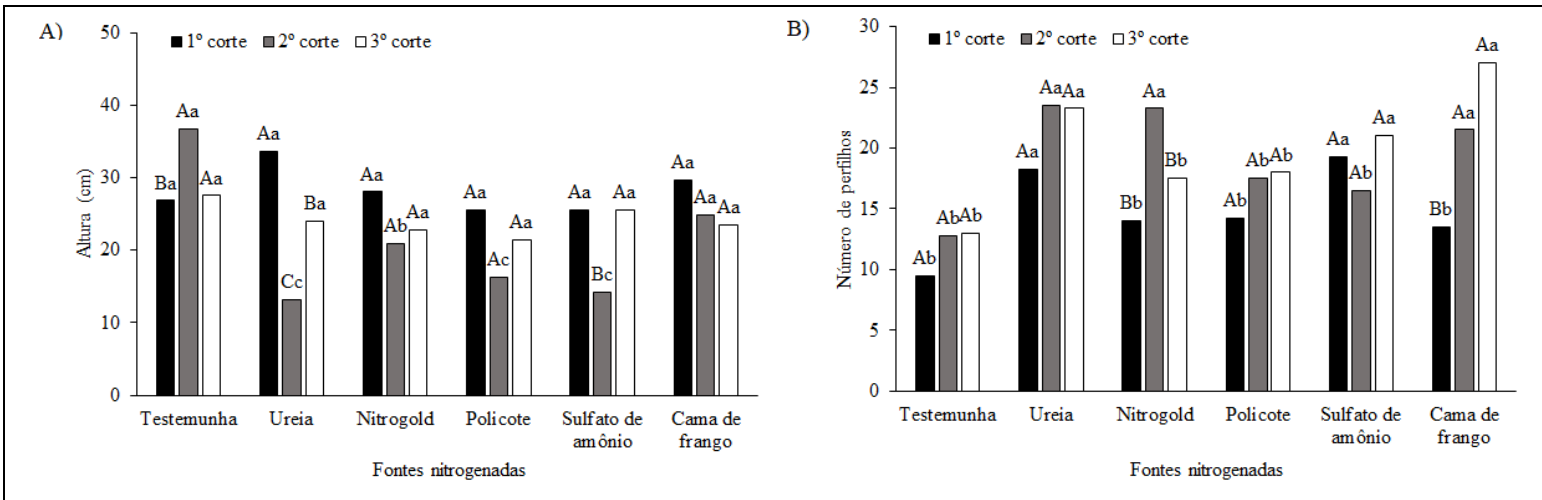

Nota: Médias seguidas pela mesma letra maiúscula dentro dos tratamentos e por letras minúsculas entre os tratamentos não diferem entre si pelo teste de Scott-Knott a 5\% de probabilidade. Means followed by the same uppercase letter within the treatments and lowercase letters between treatments do not differ from each other by the Scott-Knott test at 5\% probability.

Figura 1. Altura (A) e número de perfilhos (B) por planta do capim Tifton 85 em função de diferentes adubos nitrogenados e número de cortes. Height $(A)$ and number of tillers $(B)$ per plant in Tifton 85 grass as a function of different nitrogen fertilizers and number of cuts.

Fonte: Autoria própria. Own authorship.

Quando comparadas as fontes nitrogenadas, a testemunha sem adubação apresentou maior altura no segundo e terceiro corte, enquanto que a ureia convencional e sulfato de amônio apresentaram maior altura no primeiro corte, sendo que a ureia Nitrogold, Policote e cama de frango não obtiveram variação de altura ao longo dos diferentes cortes da forrageira. Taffarel et al. (2016) observaram variação da altura de acordo com a época de corte e com a quantidade de adubo aplicado.

Em relação ao número de perfilhos, a ureia, sulfato de amônio e cama de frango apresentaram maior média no $2^{\circ}$ e $3^{\circ}$ cortes e em relação aos demais adubos, com aumento de $78,8 \%, 61,5 \%$ e 107,7\%, respectivamente (Figura 1B). Os tratamentos submetidos a ureia Nitrogold e Policote não proporcionaram aumento significativo do perfilhamento do Tifton 85. Costa et al. (2016) ressaltam que a produção de novos perfilhos é um processo contínuo, sendo que a população da forrageira pode ser mantida por uma contínua reposição dos perfilhos mortos, sendo este mecanismo essencial para a perenidade das gramíneas.

A massa seca do capim Tifton 85 apresentou maiores médias no primeiro corte para todos as fontes nitrogenadas, entretanto a adubação com sulfato de amônio promoveu aumento significativo de $235,6 \%$ em relação a massa seca total (Figura 2). Os segundos e terceiros cortes não apresentaram diferença estatística em relação a adubação, entretanto, a massa seca foi reduzida, em média, 79,7\%, 93,7\% e 97,1\%, para folhas, colmo e total, respectivamente, quando comparado a biomassa obtida no $1^{\circ}$ e no $3^{\circ}$ corte.

Resultado corrobora com Martuscello et al. (2016), cuja aplicação de nitrogênio em pastagens proporcionou maior produção de massa seca das lâminas foliares e massa seca do 
colmo, e, com consequência, maior massa seca total. A produção de massa seca foliar é característica essencial para o crescimento das forrageiras, uma vez que a lâmina é a principal estrutura fotossintética da maioria das plantas, além de promover maior digestibilidade (MARTUSCELLO et al., 2016).

O nitrogênio quando aplicado no solo é assimilado pela forrageira e se associa às cadeias de carbono, promovendo o aumento dos constituintes celulares e, consequentemente, aumentando o vigor e a produção total de matéria seca das plantas (GALINDO et al., 2017). Além disso, afeta o acúmulo de carboidratos, aminoácidos, enzimas e fitohormônios, que promove o incremento da biomassa (BORGES et al., 2017).

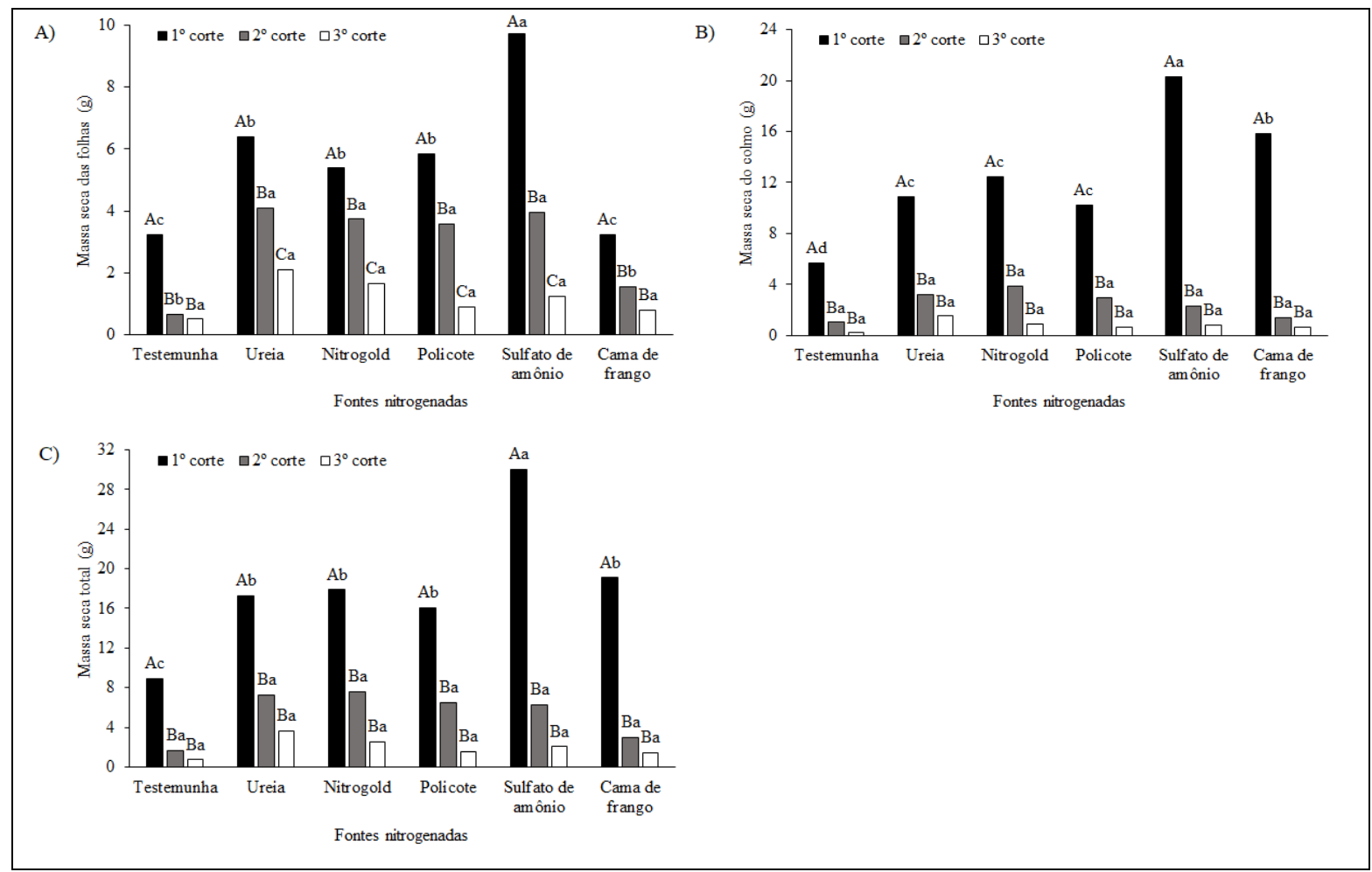

Nota: Médias seguidas pela mesma letra maiúscula dentro dos tratamentos e por letras minúsculas entre os tratamentos não diferem entre si pelo teste de Scott-Knott a 5\% de probabilidade. Means followed by the same uppercase letter within the treatments and lowercase letters between treatments do not differ from each other by the Scott-Knott test at 5\% probability.

Figura 2. Massa seca das folhas (A), massa seca do colmo (B) e massa seca total (C) do capim Tifton 85 em função de diferentes adubos nitrogenados e número de cortes. Leaf dry mass (A), stem dry mass (B) and total dry mass (C) in Tifton 85 grass as a function of different nitrogen fertilizers and number of cuts.

Fonte: Autoria própria. Own authorship.

A relação folha/colmo não diferiu entre os diferentes tipos de adubos nitrogenados, porém foi influenciada pela época de corte. A testemunha, ureia Policote e sulfato de amônio apresentaram aumento da produção de folhas em função dos cortes (Figura 3A). 


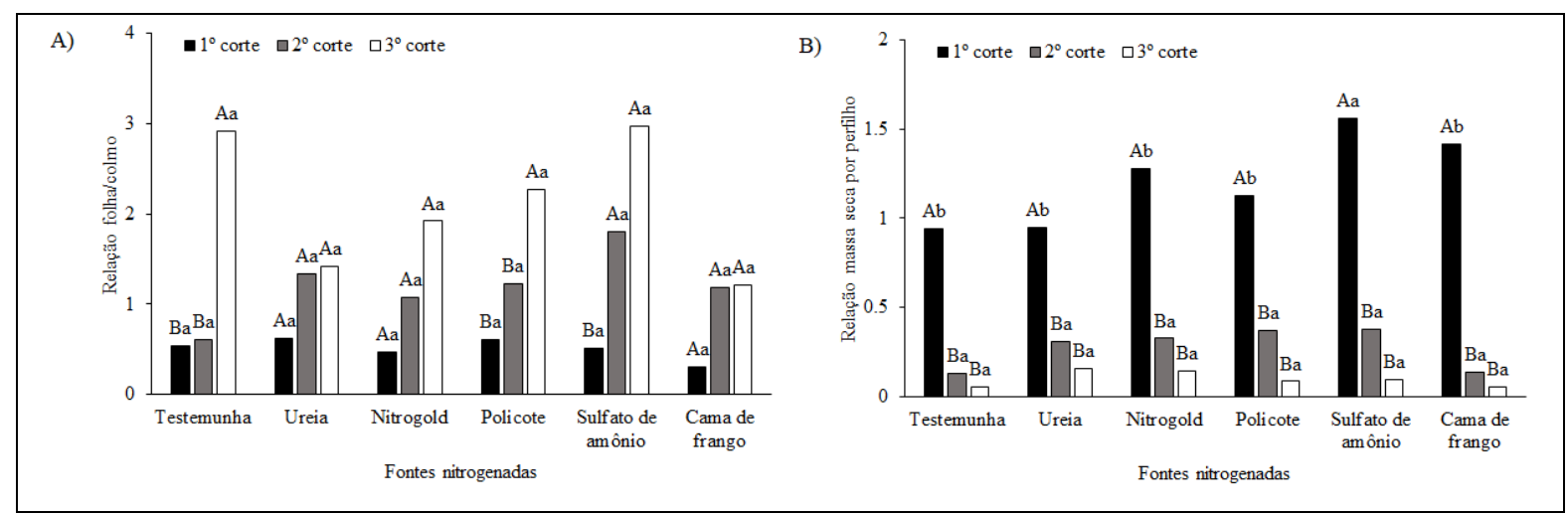

Nota: Médias seguidas pela mesma letra maiúscula dentro dos tratamentos e por letras minúsculas entre os tratamentos não diferem entre si pelo teste de Scott-Knott a 5\% de probabilidade. Means followed by the same uppercase letter within the treatments and lowercase letters between treatments do not differ from each other by the Scott-Knott test at 5\% probability.

Figura 3. Relação folha/colmo (A) e relação massa seca por perfilho (B) do capim Tifton 85 em função de diferentes adubos nitrogenados e número de cortes. Leaf/stem ratio (A) and dry mass ratio by tiller $(B)$ in Tifton 85 grass as a function of different nitrogen fertilizers and number of cuts.

Fonte: Autoria própria. Own authorship.

Resultado semelhante foi encontrado por Moreira et al. (2014), que atribuiu os resultados aos processos fisiológicos da planta de adaptação ao pastejo. A relação folha/colmo é de grande importância para a avaliação das plantas forrageiras, sendo que alta relação representa forragem com elevada concentração de proteína e digestibilidade, melhor adaptação ao pastejo e tolerância ao corte, com maior possibilidade de atender às exigências nutricionais dos ruminantes, garantindo maior ganho de peso ou produção de leite (SILVA et al., 2013).

A relação massa seca por perfilho foi maior no primeiro corte em todos os tratamentos, devido ao fato da maior produção de biomassa neste corte, com destaque para o sulfato de amônio, com acréscimo de aproximadamente $89 \%$ da biomassa por perfilhos (Figura 3B). Entretanto, no segundo e terceiro corte com o aumento de perfilhamento e redução da massa seca, houve a produção de perfilhos com menor acumulo de biomassa foliar, compostos principalmente de folhas.

Na Figura 4 fica evidente a importância da adubação nitrogenada na produtividade do capim Tifton 85. A maior produtividade estimada foi para o sulfato de amônio durante o primeiro corte, devido este tratamento obter a maior massa seca total, além de promover a maior média de produtividade entre os cortes. 


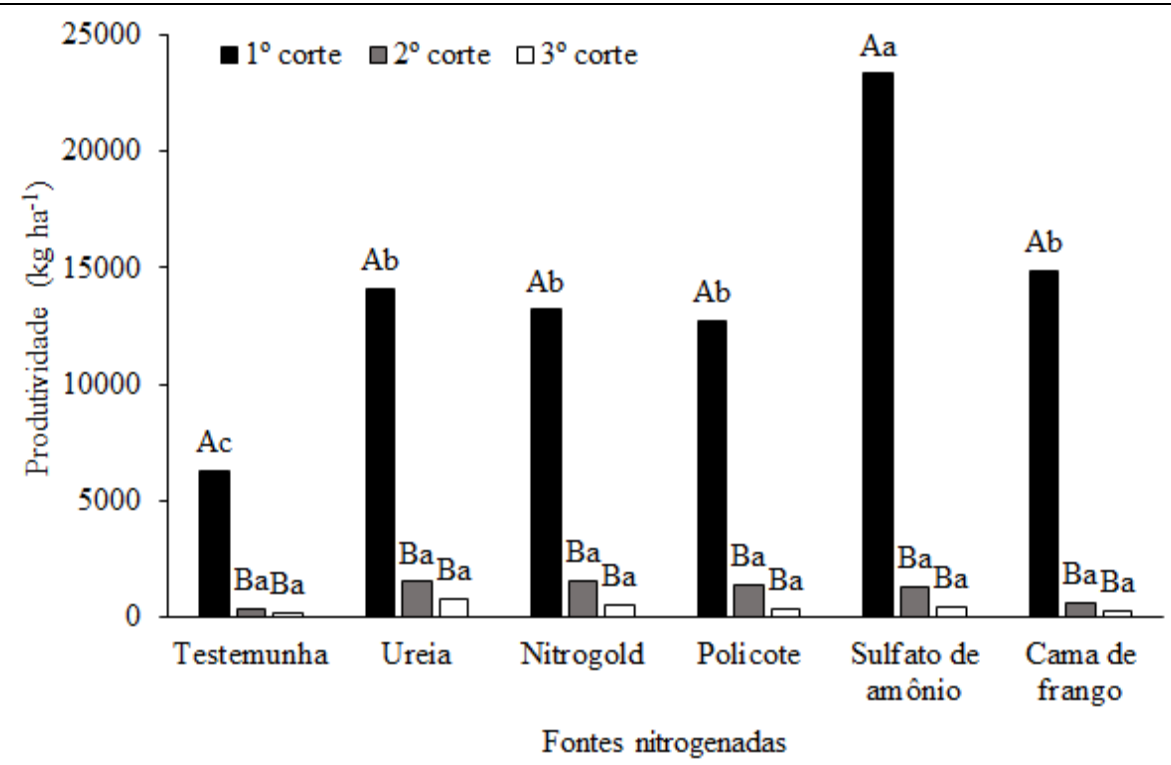

Nota: Médias seguidas pela mesma letra maiúscula dentro dos tratamentos e por letras minúsculas entre os tratamentos não diferem entre si pelo teste de Scott-Knott a 5\% de probabilidade. Means followed by the same uppercase letter within the treatments and lowercase letters between treatments do not differ from each other by the Scott-Knott test at $5 \%$ probability.

Figura 4. Produtividade estimada do capim Tifton 85 em função de diferentes adubos nitrogenados e número de cortes. Estimated productivity in Tifton 85 grass as a function of different nitrogen fertilizers and number of cuts.

Fonte: Autoria própria. Own authorship.

Assim como para os valores de massa seca total, não houve diferença estatística entre as adubações no $2^{\circ}$ e $3^{\circ}$ corte, sendo que para todos os tipos de fertilizantes o primeiro corte foi o mais produtivo. A drástica redução da adubação entre o primeiro e segundo corte (média de $92,1 \%$ ) indica a necessidade de parcelamento da adubação de modo a manter a produtividade constantes entre os cortes.

$\mathrm{O}$ uso de adubos nitrogenados demostrou ser uma alternativa promissora a ser implantada em campo, proporcionando aumentos de produtividade de $109,6 \%$ a até $270 \%$ no primeiro corte, e de $102 \%$ a até $269 \%$ na produtividade total, resultando em maior biomassa disponível para o gado e maior capacidade de lotação animal. Dupas et al. (2016) também encontraram maior produtividade do capim-braquiária quando submetido a aplicação com sulfato de amônio, sendo que a ureia protegida apresentou maiores resultados ao longo do tempo, no final do quarto corte.

Produtividades semelhante foram encontradas por Gomes et al. (2015), com produtividades total de até 35051 e $23170 \mathrm{~kg} \mathrm{MS} \mathrm{ha-1}$, com e sem irrigação respectivamente; por Moreira et al. (2014) que atingiu $18148 \mathrm{MS} \mathrm{ha}^{-1}$ em três cortes; e por Sanches et al. (2017) com produtividade de até $27,78 \mathrm{~kg} \mathrm{MS} \mathrm{ha}^{-1}$ para a forrageira submetida a irrigação, todos avaliando o efeito de diferentes doses de nitrogênio na cultura.

Os maiores valores de massa seca e de produtividade obtidos pelo sulfato de amônio podem ser atribuídos a ausência de volatilização de $\mathrm{NH}_{3}$ da fonte, a qual pode ter ocorrido com os outros fertilizantes amídicos/amoniacais (MEGDA et al., 2013). Além disso, a presença de enxofre como componentes deste fertilizante influencia no aumento de 
produtividade, sendo o $\mathrm{S}$ essencial para o metabolismo do nitrogênio e síntese de proteínas e aminoácidos (MARSCHNER, 2011; GALINDO et al., 2018a).

A ureia, por ser uma fonte solúvel em água, é rapidamente convertida em formas que podem ser perdidas por lixiviação ou volatilização, o que diminui a eficiência de utilização do nitrogênio (FAN et al., 2004). O uso de novas tecnologias para redução das perdas por volatilização da ureia como a utilização de aditivos para inibição da ação da urease no solo, no caso da ureia Policote, ou com revestimento de enxofre, como a ureia Nitrogold, não apresentaram diferença quando comparada a ureia convencional. Uma explicação para esse efeito foi relatada por Martins et al. (2014), que concluíram que a ureia revestida por polímeros tem desempenho semelhante ao da ureia comum, quando aplicada em período com chuvas frequentes e suficientes para a imediata solubilização e incorporação de ambos os fertilizantes em camadas internas do solo, sendo superior somente em épocas de veranicos. Como neste experimento a irrigação foi constante para todos os tratamentos, não observou o efeito das diferentes fontes de ureia.

De forma semelhante, estudos sobre fontes de $\mathrm{N}$ de liberação lenta (ureia recoberta), em comparação com formas mais solúveis (ureia e sulfato de amônio), não têm evidenciado diferenças de produtividade (BERNARDES et al., 2015). Dupas et al. (2016) observaram que a longo prazo não há diferença entre os fertilizantes nitrogenados, sendo que quando a comparação é feita em cada período de crescimento demonstra fatores intrínsecos ao meio ambiente, ao fertilizante e à planta interferem na resposta do capim a adubação nitrogenada.

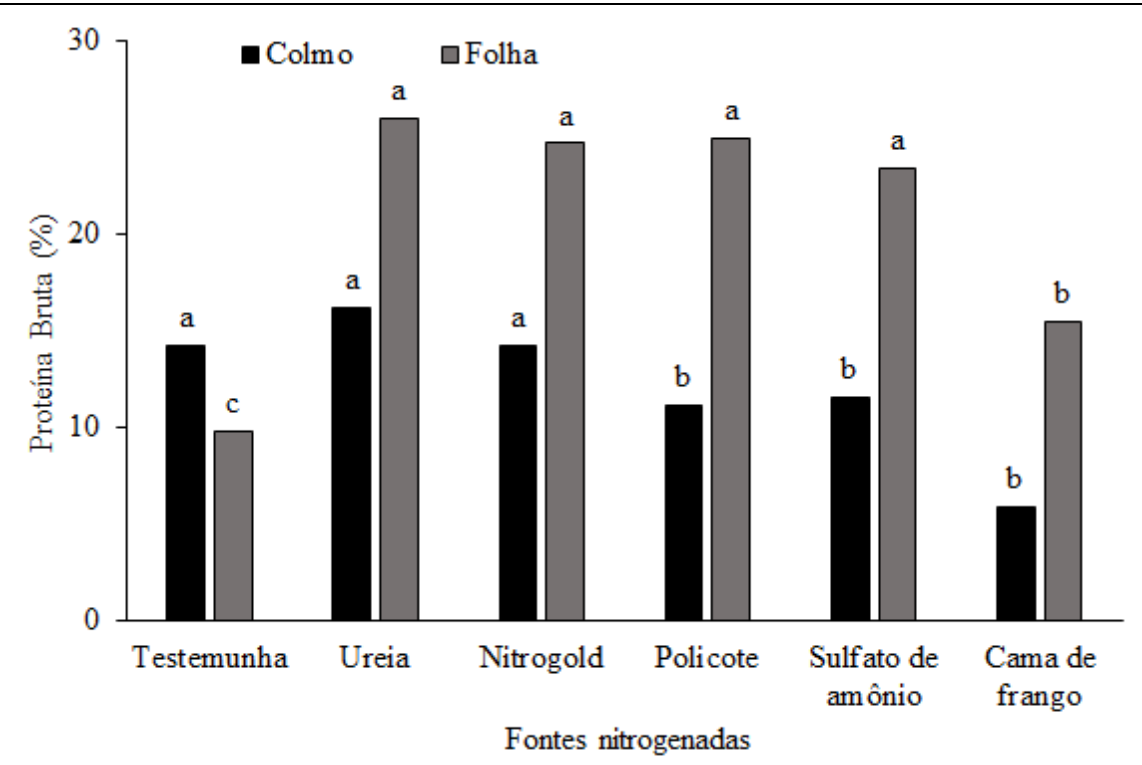

Nota: Médias seguidas pela mesma letra maiúscula dentro dos tratamentos e por letras minúsculas entre os tratamentos não diferem entre si pelo teste de Scott-Knott a 5\% de probabilidade. Means followed by the same uppercase letter within the treatments and lowercase letters between treatments do not differ from each other by the Scott-Knott test at $5 \%$ probability.

Figura 5. Teor de proteína bruta no capim Tifton 85 em função de diferentes adubos nitrogenados após três cortes. Crude protein content in Tifton 85 grass as a function of different nitrogen fertilizers after three cuts.

Fonte: Autoria própria. Own authorship. 
Em relação aos teores de proteína bruta $(\mathrm{PB})$ do capim Tifton 85, a adubação nitrogenada promoveu maior aumento da PB nas folhas do que no colmo, sendo que na testemunha o nitrogênio se concentrava no colmo (Figura 5). Destaque para a ureia e ureia com Nitrogold, que promoveram maior acúmulo tanto no colmo quanto nas folhas. A adubação nitrogenada promoveu aumento de até $164 \%$ na concentração de proteína foliar.

Teores de proteína bruta semelhantes foram encontrados em trabalho de Oliveira et al. (2011), Quaresma et al. (2011) e Sanches et al. (2017), variando de acordo com a dose de nitrogênio aplicado, demostrando a eficiência da adubação em elevar o teor proteico da forragem. Taffarel et al. (2016) afirmam que o capim Tifton 85 apresenta boa qualidade nutricional, mesmo na ausência de adubação nitrogenada, sendo que valores de proteína bruta abaixo de $7 \%$ limitariam o consumo para bovinos.

De acordo com Galindo et al. (2018b), com a aplicação do nitrogênio a tendência é de aumentar a disponibilidade de nitrogênio à gramínea forrageira, culminando no aumento da absorção e nos teores de $\mathrm{N}$ em parte aérea, aumentando consequentemente o teor de proteína bruta. O nitrogênio promove incremento no teor da proteína bruta e melhora na digestibilidade da matéria seca, melhorando as características nutricionais das pastagens (RIBEIRO e PEREIRA, 2011). A ausência ou baixa dose de fertilização nitrogenada em pastagens reduz os teores de proteína bruta e de proteína degradável no rúmen, o que pode limitar o desempenho de ruminantes com maiores exigências proteicas (TAFFAREL et al., 2016).

\section{CONCLUSÃO}

A adubação nitrogenada proporciona melhoria das características produtivas e bromatológicas do capim Tifton 85 .

O uso de sulfato de amônio promoveu maior produtividade e acúmulo de nitrogênio pelo capim Tifton 85, após três cortes.

A produtividade do capim Tifton 85 decresce em função do número de cortes, enquanto ocorre um aumento da relação folha/colmo, o que indica a necessidade do parcelamento da adubação nitrogenada.

\section{REFERÊNCIAS BIBLIOGRÁFICAS}

BERNARDES, T. G.; SILVEIRA, P. M.; MELO CARVALHO, M. T.; MADARI, B. E.; CARVALHO, M. D. C. S. Produtividade do feijoeiro irrigado em razão de fontes de adubo nitrogenado estabilizado e de liberação controlada. Revista Ceres, Viçosa, v. 62, n. 6, p.507513, 2015. Disponível em: http://www.ceres.ufv.br/ojs/index.php/ceres/article/view/1334. Acesso em: 27 ago. 2019.

BORGES, B. M.; SILVEIRA, M. L.; CARDOSO, S. S.; MOLINE, E. F.; COUTINHO NETO, A. M.; LUCAS, F. T.; MURAOKA, T.; COUTINHO, E. L. Growth, herbage accumulation, and nutritive value of 'Tifton 85 ' bermudagrass as affected by nitrogen 
fertilization strategies. Crop Science, Madison, v. 57, n. 6, p.3333-3342, 2017. Disponível em: DOI: 10.2135/cropsci2016.10.0890. Acesso em: 25 ago. 2019.

BURTON, G.; GATES, R.; HILL, G. Registration of Tifton 85' bermudagrass. Crop Science, Madison, v. 33, n. 3, p.644-645, 1993. Disponível em: DOI: 10.2135/cropsci1993.0011183X003300030045x. Acesso em: 18 ago. 2019.

CHAGAS, P. H. M.; GOUVEIA, G. C. C.; COSTA, G. G. S.; BARBOSA, W. F. S.; ALVES, A. C. Volatilização de amônia em pastagem adubada com fontes nitrogenadas. Journal of Neotropical Agriculture, Cassilândia, v. 4, n. 2, p.76-80, 2017. Disponível em: DOI: https://doi.org/10.32404/rean.v4i2.1301. Acesso em: 25 ago. 2019.

COSTA, N. D. L.; PAUlinO, V. T.; MAGAlhÃES, J. A.; RODRIGUES, B. H. N.; SEIXAS SANTOS, F. J. Eficiência do nitrogênio, produção de forragem e morfogênese do capim-massai sob adubação. Nucleus, Sydney, v. 13, n. 2, p.173-182, 2016. Disponível em: DOI: http://dx.doi.org/10.3738/1982.2278.1695. Acesso em: 21 ago. 2019.

DUPAS, E.; BUZETTI, S.; RABÊLO, F. H. S.; SARTO, A. L.; CHENG, N. C.; GALINDO, F. S.; DINALLI, R. P.; NIRO GAZOLA, R. Nitrogen recovery, use efficiency, dry matter yield, and chemical composition of palisade grass fertilized with nitrogen sources in the cerrado biome. Australian Journal of Crop Science, Lismore, v. 10, n. 9, p.1330-1338, 2016. Disponível em: DOI: 10.21475/ajcs.2016.10.09.p7854. Acesso em: 25 ago. 2019.

FAN, X.; LI, F.; LIU, F.; KUMAR, D. Fertilization with a new type of coated urea: Evaluation for nitrogen efficiency and yield in winter wheat. Journal of Plant Nutrition, New York, v. 27, n. 5, p.853-865, 2004. Disponível em: DOI: https://doi.org/10.1081/PLN120030675. Acesso em: 15 ago. 2019.

GALINDO, F. S.; BUZETTI, S.; DUPAS, E.; LUDKIEWICZ, M. G. Z. Application of different nitrogen doses to increase nitrogen efficiency in mombasa guinegrass ('Panicum maximum'cv. mombasa) at dry and rainy seasons. Australian Journal of Crop Science, Lismore, v. 11, n. 12, p.1657-1664, 2017. Disponível em: DOI: 10.21475/ajcs.17.11.12.pne907. Acesso em: 15 ago. 2019.

GALINDO, F. S.; BUZETTI, S.; TEIXEIRA FILHO, M. C. M.; DUPAS, E.; CARVALHO, F. D. C. Manejo da adubação nitrogenada no capim-mombaça em função de fontes e doses de nitrogênio. Revista de Ciências Agrárias, Lisboa, v. 41, n. 4, p.31-40, 2018a. Disponível em: http://www.scielo.mec.pt/pdf/rca/v41n4/v41n4a04.pdf. Acesso em: 20 ago. 2019.

GALINDO, F. S.; BUZETTI, S.; TEIXEIRA FILHO, M. C. M.; DUPAS, E.; LUDKIEWICZ, M. G. Z. Acúmulo de matéria seca e nutrientes no capim-mombaça em função do manejo da adubação nitrogenada. Journal of Neotropical Agriculture, Cassilândia, v. 5, n. 3, p.1-9, 2018b. Disponível em: DOI: https://doi.org/10.32404/rean.v5i3.2132. Acesso em: 18 ago. 2019.

GOMES, E. P.; RICKLI, M. E.; CECATO, U.; VIEIRA, C. V.; SAPIA, J. G.; SANCHES, A. C. Produtividade de capim Tifton 85 sob irrigação e doses de nitrogênio. Revista Brasileira de Engenharia Agrícola e Ambiental, Campina Grande, v. 19, n. 4, p.317-323, 2015. 
Disponível em: http://www.scielo.br/scielo.php?pid=S141543662015000400317\&script=sci_abstract\&tlng=pt. Acesso em: 19 ago. 2019.

MARSCHNER, H. Marschner's mineral nutrition of higher plants. London: Academic Press, 2011. 583 p.

MARTINS, I. S.; CAZETTA, J. O.; FUKUDA, A. J. F. Condições, modos de aplicação e doses de ureia revestida por polímeros na cultura do milho. Pesquisa Agropecuária Tropical, Goiânia, v. 44, n. 3, p.271-279, 2014. Disponível em: http://www.scielo.br/pdf/pat/v44n3/a10v44n3.pdf. Acesso em: 10 ago. 2019.

MARTUSCELLO, J.; MAJEROWICZ, N.; CUNHA, D.; AMORIM, P.; BRAZ, T. Características produtivas e fisiológicas de capim-elefante submetido à adubação nitrogenada. Archivos de Zootecnia, Córdoba, v. 65, n. 252, p.565-570, 2016. Disponível em: https://www.uco.es/ucopress/az/index.php/az/article/view/1927/1401. Acesso em: 10 ago. 2019.

MEGDA, M. X. V.; TRIVELIN, P. C. O.; FRANCO, H. C. J.; OTTO, R.; VITTI, A. C. Eficiência agronômica de adubos nitrogenados em soqueira de cana-de-açúcar colhida sem queima. Pesquisa Agropecuária Brasileira, Brasília, v. 47, n. 12, p.1681-1690, 2013. Disponível em: https://doi.org/10.1590/S0100-204X2012001200002. . Acesso em: 15 ago. 2019.

MOREIRA, A. L.; FAGUNDES, J. L.; YOSHIHARA, E.; BACKES, A. A.; BARBOSA, L. T.; HEINRICHS, R. Production of sheep grazing on nitrogen-fertilized Tifton 85 grass in continuous stocking. Acta Scientiarum. Animal Sciences, Maringá, v. 36, n. 1, p.63-69, 2014. Disponível em: http://www.scielo.br/pdf/asas/v36n1/v36n1a08.pdf. Acesso em: 12 ago. 2019.

OLIVEIRA, M.; PEREIRA, O.; RIBEIRO, K.; SANTOS, M.; CHIZZOTTI, F.; CECON, P. Produção e valor nutritivo do capim-coastcross sob doses de nitrogênio e idades de rebrotação. Arquivo Brasileiro de Medicina Veterinária e Zootecnia, Belo Horizonte, v. 63, n. 3, p.694-703, 2011. Disponível em: DOI: https://doi.org/10.1590/S010209352011000300022. Acesso em: 15 ago. 2019.

QUARESMA, J. P. D. S.; ALMEIDA, R. G.; ABREU, J. G.; SILVA CABRAL, L.; OLIVEIRA, M. A.; CARVALHO, D. M. G. Produção e composição bromatológica do capim-tifton 85 (Cynodon spp.) submetido a doses de nitrogênio. Acta Scientiarum. Animal Sciences, Maringá, v. 33, n. 2, p.145-150, 2011. Disponível em: DOI: https://doi.org/10.4025/actascianimsci.v33i29261. Acesso em: 21 ago. 2019.

RIBEIRO, K. G.; PEREIRA, O. G. Produtividade de matéria seca e composição mineral do capim-tifton 85 sob diferentes doses de nitrogênio e idades de rebrotação. Ciência e Agrotecnologia, Lavras, v. 35, n. 4, p.811-816, 2011. Disponível em: DOI: https://doi.org/10.1590/S1413-70542011000400022. Acesso em: 25 ago. 2019.

SANCHES, A. C.; GOMES, E. P.; RICKLI, M. E.; FRISKE, E.; FASOLIN, J. P. Productivity and nutritive value of Tifton 85 in summer, with and without irrigation under different nitrogen doses. Engenharia Agrícola, Jaboticabal, v. 37, n. 2, p.246-256, 2017. Disponível 
em: DOI: https://doi.org/10.1590/1809-4430-eng.agric.v37n2p246-256/2017. Acesso em: 10 ago. 2019.

SILVA, D. R. G.; PINHO COSTA, K. A.; FAQUIN, V.; OLIVEIRA, I. P.; BERNARDES, T. F. Doses e fontes de nitrogênio na recuperação das características estruturais e produtivas do capim-marandu. Revista Ciência Agronômica, Fortaleza, v. 44, n. 1, p.184-191, 2013. Disponível em: http://www.scielo.br/pdf/rca/v44n1/a23v44n1.pdf. Acesso em: 22 ago. 2019.

TAFFAREL, L. E.; MESQUITA, E. E.; CASTAGNARA, D. D.; GALBEIRO, S.; COSTA, P. B.; DE OLIVEIRA, P. S. R. Tifton 85 grass responses to different nitrogen levels and cutting intervals. Semina: Ciências Agrárias, Londrina, v. 37, n. 4, p. 2067-2083, 2016. Disponível em: DOI: http://dx.doi.org/10.5433/1679-0359.2016v37n4p2067. Acesso em: 25 ago. 2019.

THE R DEVELOPMENT CORE TEAM. R: a language and environment for statistical computing. $\quad[S . \quad$ l. $]$. 2013. $\quad$ Disponível http://softlibre.unizar.es/manuales/aplicaciones/r/fullrefman.pdf. Acesso em: 10 ago. 2019.

TIECHER, D. D.; ROCHA, M. G. D.; PÖTTER, L.; SALVADOR, P. R.; BERGOLI, T. L.; MILANESI, G. D. Morphogenesis and structure of Tifton 85 cultivated in subtropical climate and fertilized with nitrogen. Acta Scientiarum. Animal Sciences, Maringá, v. 38, n. 4, p.389-393, 2016. Disponível em: DOI: https://doi.org/10.4025/actascianimsci.v38i4.32147. Acesso em: 26 ago. 2019. 